\title{
Afectación lítica multifocal de la columna vertebral
}

\author{
Cordido-Henríquez F. ${ }^{1}$, Gutiérrez-Pantoja MA. ${ }^{1}$, Valdés-Fernández B. ${ }^{1}$, Campos-Rivas R. ${ }^{1}$, \\ Molina-López-Nava P. ${ }^{2}$
}

Sanid. mil. 2021; 77 (1): 45-46, ISSN: 1887-8571

\section{DESCRIPCIÓN DEL CASO}

Paciente varón de 59 años, natural de Bolivia, sin alergias conocidas y $\sin$ antecedentes personales de interés, que fue
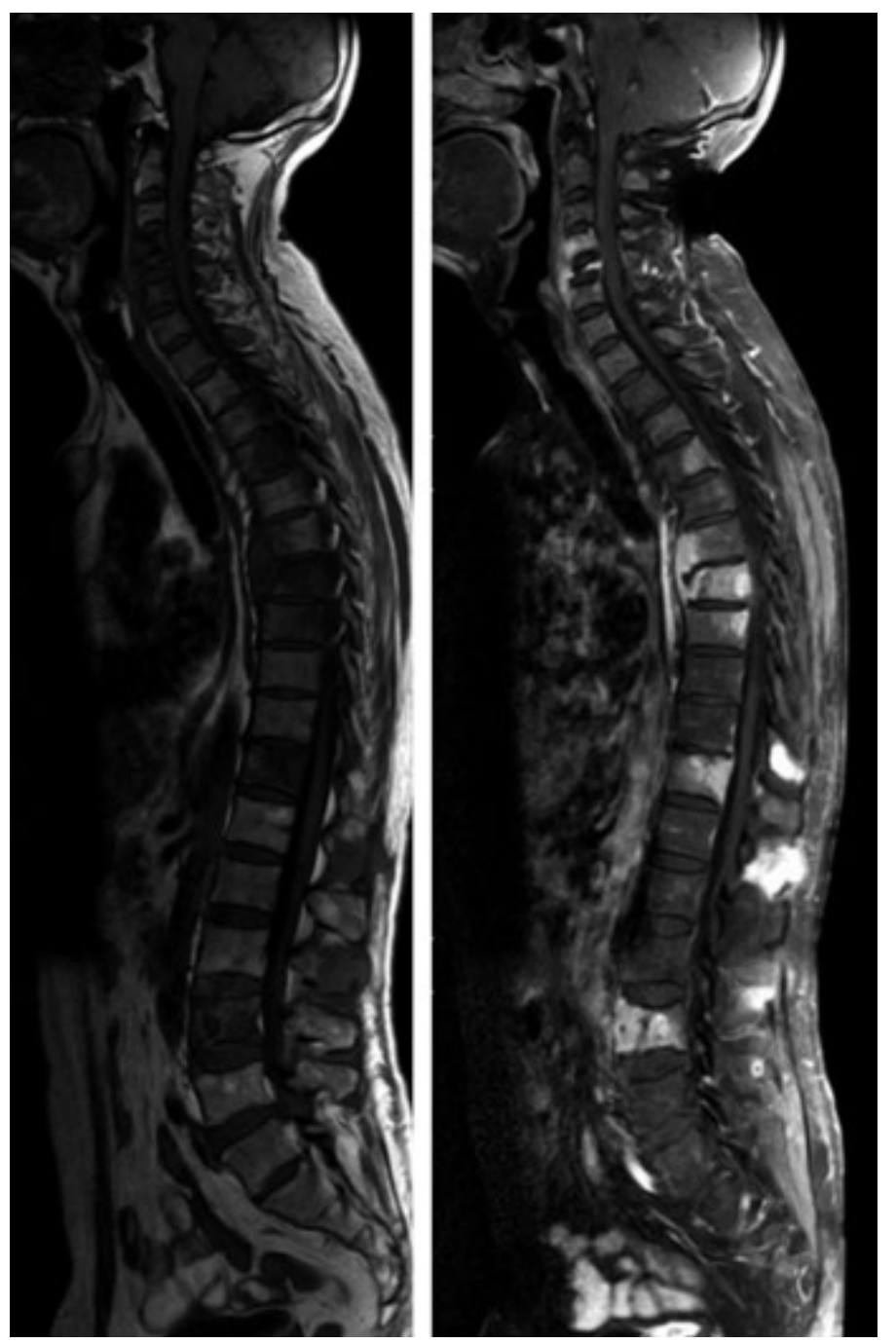

Figuras 1 y 2. $R M$ de columna total cortes sagitales $T 1$ sin y tras la administración de gadolinio: afectación multifocal vertebral contigua con abscesos de partes blanda asociados y afectación subligamentosa. derivado a consultas de neurocirugía por lumbalgia en mayo de 2019. El paciente refería un cuadro clínico de unos 7 meses de evolución de lumbalgia de características mal definidas, asociando semanas después dolor en ambas escápulas, cervicalgia, parestesias en ambas manos, debilidad en miembros inferiores, perdida de $8 \mathrm{~kg}$ de peso y astenia.

A la exploración física presentaba un aumento de partes blandas en región paracervical derecha y apofisalgia en región cervical, sin focalidad neurológica ni otros signos de interés. En la analítica destacaban reactantes de fase aguda elevados con VSG de $73 \mathrm{~mm} / \mathrm{h}$, fibrinógeno de $743 \mathrm{mg} / \mathrm{dl}$ y PCR de $5,6 \mathrm{mg} / \mathrm{dl}$.

Se realizaron varios estudios de imagen entre ellos una RM de columna total donde se evidenciaban múltiples lesiones focales líticas vertebrales en todo los niveles (cervical, dorsal y lumbar) que afectaban tanto a los cuerpos vertebrales como a los elementos posteriores, con abscesos/masas de partes blandas paravertebrales extradurales asociadas (Figuras 1 y 2), hallazgos que radiológicamente planteaban como diagnóstico diferencial un origen metastásico de las mismas, enfermedad infiltrativa difusa de la médula ósea o una etiología infecciosa/inflamatoria. También se realizó una TC de columna cervicodorsal donde se confirmaron las lesiones líticas con masa de partes blandas que afectaban a varias vértebras cervicodorsales así como múltiples implantes pleurales bilaterales y derrame pleural izquierdo (Figuras 3 y 4).

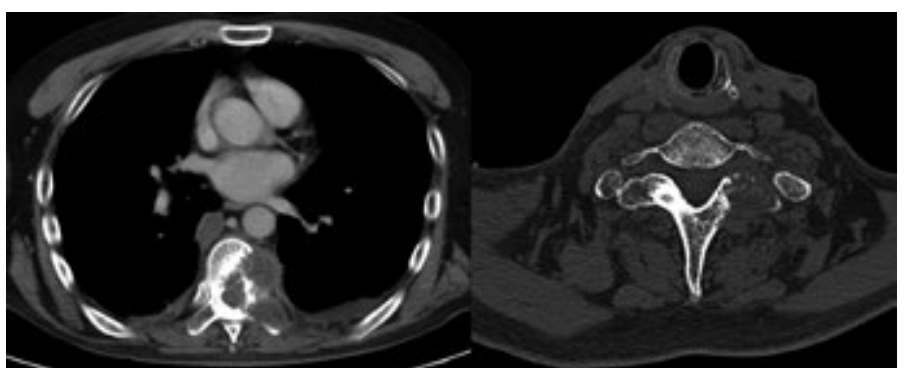

Figuras 3 y 4. TC cervicodorsal cortes axiales de tórax y columna cervical respectivamente con CIV: implantes pleurales $y$ lesiones líticas en cuerpos vertebrales que afectan a elementos posteriores.

\footnotetext{
${ }^{1}$ Médico civil. Hospital Central de la Defensa Gómez Ulla. Servicio de Radiodiagnóstico. Madrid. España.

${ }^{2}$ Coronel Médico. Hospital Central de la Defensa Gómez Ulla. Servicio de Radiodiagnóstico. Madrid. España.
}

Recibido: 16 de junio de 2020

Aceptado: 21 de diciembre de 2020

doi: $10.4321 /$ S1887-85712021000100008 


\section{Diagnóstico: Espondilitis tuberculosa}

Los hallazgos por imagen de este paciente planteaban un abanico diagnóstico con diferentes implicaciones tanto en el manejo terapéutico como en el pronóstico del mismo. Por este motivo se decidió realizar un estudio histopatológico y microbiológico mediante biopsia con aguja de gruesa de una de las masas de partes blandas de la columna evidenciándose una inflamación granulomatosa necrotizante, con BAAR positivos, compatibles con Mycobacterium tuberculosis complex. También se analizó una muestra del líquido pleural apreciándose agrupaciones nodulares de elementos epitelioides sugestivas de granulomas, sobre hiperplasia mesotelial reactiva y componente inflamatorio mixto. Por lo tanto, los hallazgos clínico-patológicos y radiológicos del paciente se corresponden con una espondilitis tuberculosa también llamada tuberculosis (TBC) espinal.

La TBC es una enfermedad con una prevalencia relativamente frecuente en países en vías de desarrollo y con una incidencia en aumento en el resto de países por fenómenos migratorios y por el aumento de la incidencia del virus de inmunodeficiencia humana ${ }^{1}$. La TBC espinal es una forma destructiva de tuberculosis que ocurre en el $1 \%$ de los pacientes con TBC pulmonar y representa el 50\% de los casos de TBC con afectación musculoesquelética ${ }^{2}$. Habitualmente dos o más vértebras contiguas se afectan por diseminación hematógena a través de las arterias intervertebrales. También se han descrito casos de espondilitis multifocal no contigua aunque son menos frecuentes ${ }^{1,3}$.

$\mathrm{Su}$ diagnóstico de presunción se basa en una combinación de manifestaciones clínicas, hallazgos de laboratorio y pruebas de imagen, ya que ninguno de estos parámetros de forma aislada es patognomónico ${ }^{3}$. La columna torácica es la región más afectada, luego la zona lumbar y la cervical. De forma característica se observa colapso y acuñamiento anterior de los cuerpos vertebrales produciendo deformidad en giba ${ }^{2}$. Puede existir destrucción o no de los discos intervertebrales y en ocasiones solo afectar a elementos posteriores. Es frecuente la formación de masas de partes blandas epidurales y abscesos paravertebrales disecantes ${ }^{4}$.

Las manifestaciones clínicas incluyen síndrome constitucional, dolor de espalda, dolor a la palpación, deformidades espinales, paraparesias y los trastornos sensitivos entre otros ${ }^{2}$.

En el diagnóstico diferencial debemos considerar la osteomielitis piógena, donde se afecta más la columna lumbar, suele haber afectación del disco intervertebral y la afectación de elementos posteriores es más rara. Las metástasis óseas pueden ser muy difíciles de diferenciar al presentar un comportamiento muy similar en las pruebas de imagen, por lo que en ausencia de un tumor primario conocido, el diagnóstico en ocasiones solo es posible mediante el estudio histológico de las mismas. Otras posibilidades son la osteomielitis fúngica o la espondilitis brucelósica ${ }^{4}$. La realización de una biopsia para obtener un diagnóstico histopatológico y microbiológico definitivo es recomendable para confirmar la sospecha de TBC espinal ${ }^{5}$.

El pronóstico dependerá de un diagnóstico y tratamientos apropiados de forma precoz. La ausencia de tratamiento puede llevar al colapso vertebral progresivo, déficits neurológicos irreversibles e incluso la muerte. El tratamiento de elección es la medicación antituberculosa a largo plazo compuesta por una cuádruple terapia. La descompresión y desbridamiento quirúrgico están indicados en los casos donde existe clínica neurológica principalmente compresiva, falta de respuesta a tratamiento farmacológico y deformidad incapacitante o progresiva, entre otros $^{5}$.

Actualmente el paciente se encuentra en seguimiento por medicina interna y neurocirugía, recibe tratamiento antibiótico para $\mathrm{TBC}$, es portador de una órtesis semirrígida dorsolumbar y collarín blando cervical. Se encuentra clínicamente asintomático y en la RM de control de columna total realizada se aprecia una estabilidad de las lesiones ya conocidas.

\section{BIBLIOGRAFÍA}

1. Emel E, Güzey FK, Güzey D, Bas NS, Sel B, Alatas I. Non-contiguous multifocal spinal tuberculosis involving cervical, thoracic, lumbar and sacral segments: a case report. Eur Spine J. 2006; 15(6): 1019-1024.

2. Garg RK, Somvanshi DS. Spinal tuberculosis: a review. J Spinal Cord Med. 2011; 34(5): 440-454.

3. Kanna RM, Babu N, Kannan M, Shetty AP, Rajasekaran S. Diagnostic accuracy of whole spine magnetic resonance imaging in spinal tuberculosis validated through tissue studies. Eur Spine J. 2019; 28(12): 3003-3010.

4. Ross. Diagnóstico por imagen. Columna. Parte IV. Infecciones y enfermedades inflamatorias. Sección 1, p 10-13. MARBAN. ISBN 978-84-7101-760-4.

5. Chaudhary K, Dhawale A, Chaddha R, Laheri V. Spinal tuberculosis - an update. J Clin Orthop. 2017; 2(1): 31-42. 